\title{
A SATELLITE SYSTEM FOR RADIO ASTRONOMICAL MEASUREMENTS AT LOW FREQUENCIES
}

\author{
by J. K. Alexander and R. G. Stone
}

(N. A. S. A. Goddard Space Flight Center Greenbelt, Maryland, U. S. A.)

RÉsumé. - En 1962 au "Goddard Space Flight Center » on a commencé l'étude des observations à exécuter à bord d'un satellite radio-astronomique. Cette étude a ensuite été étendue aux antennes, aux radiomètres et aux équipements annexes. On a abouti à la conception d'un satellite spécialisé dans les observations radioastronomiques aux fréquences inférieures à la limite imposée par l'ionosphère. On montre que l'on peut construire une antenne en $V$ dont le lobe principal aurait $30^{\circ}$ de largeur à demi puissance, un lobe arrière à - 18 db pour fréquences près de $5 \mathrm{MHz}$. Avec 4 éléments de 250 mètres de longueur formant un double $V$ ou un $X$, on peut obtenir un certain gain par rapport à un dipôle jusqu'à $0,3 \mathrm{MHz}$. On a développé un radiomètre (du type RYLE-VonBERG) dont la fréquence d'accord est modifiée de façon discontinue et comprenant une source de bruit de comparaison avec une dynamique de 70 db et une précision de $\pm 0,5 \mathrm{db}$. De même un instrument simple et précis permettant de mesurer les deux composantes de l'impédance d'antenne a été mis au point pour l'utilisation en satellite. L'étude de la Galaxie, la physique solaire et l'astronomie planétaire pourraient tirer un bénéfice considérable d'un satellite stabilisé par gradient de gravité, placé sur une orbite circulaire à $6000 \mathrm{~km}$. d'altitude et permettant des observations entre 0,3 et $10 \mathrm{MHz}$.

A вsткRAст. - A study program was initiated at the Goddard Space Flight Center in 1962 to survey the astronomical observations most readily and profitably performed by an orbiting radio observatory, to analyze the antenna configurations most appropriate for such a mission and to develop the radiometers and other supporting instrumentation required for a radio astronomy satellite. This study has culminated in the conceptual design of a spacecraft intended solely for radio astronomical observations at wavele $n$ gths beyond the ionospheric cut-off. By utilizing long (250 m) antrina elements with a terminating resistance placed an odd number of quarter-uavelengths from the end, a $I^{\prime}$-antenna can be formed having a beamuidth less than $30^{\circ}$ and an 18 db front-to-back ratio over a band of frequenries near $5 \mathrm{MHz}$. Proper combinations of four such long elements in a double-V or $X$ configuration, furthermore 'an be made to yield some gain over a, dipole, for observations as low as $0.3 \mathrm{MHz}$. A step-frequency, RYLE-VoNBERG radiometer which employs an all solid-state-component comparison noise source has been developed to perform wer a 70 db dynamic range with a relative accuracy of $=1.5 \mathrm{db}$. A simple, precise instrument to measure both the resistive and reactive components of antenna impedance has also been developed for satellite use. Observations with this system from a gravity-gradient stabilized sqacecraft in a $6000 \mathrm{~km}$ orbit would afford significant contributions to galactic studies, solar physics, and planetary astronomy by extending radio observations to frequencies in the range 03 to $10 \mathrm{MHz}$.

l'eзюле. - - В 1962 I' в «Goddard Space Flight ('enter» блло пачато изучение наблюдений для провеқепия лх с борта радиоастрономического епутника. Это пзучение было затем распространено па аптенш, па радиометры и па придаточпые оспапепия. Ӭто изучение привело к концепции

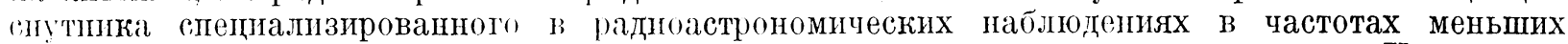
предела налагаемого ионосферой. Показано, что можно постропт, антенну в форме $\mathbf{V}$, главный .'пестюк которой имел-бы, $30^{\circ}$ ппришы при полумошности, задний лепесток - 18 бол. гр. и

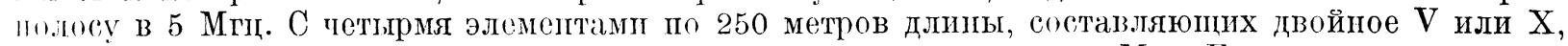
мояно получить пекоторое усиненю по срапнепию с диполем, до 0,3 Мгц. Ныл изучен радиометь (Tinil Ryle-Vonberg), частота пастройкп которого прерывисто изменяется и содержапим исто-

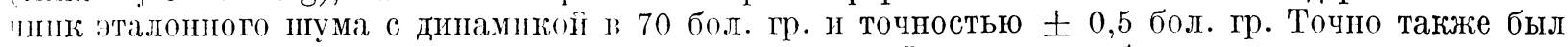
выработал простой и точный илструмент, лозволяющий измерять обе составляюшие антенного шмедепца, для испольвовапия па (путнию. Нсследование Галактики, физика Солнца и астроцомия планет могут пзвлечь значительную по.тьзу от спутника, стабилизированного на градиент ешы тяжести, выведенного на крчторую орбиту на 6000 км высоты и позволяющего делать наблюдения между 0,3 и 10 мгц. 


\section{INTRODUCTION}

During the first five years of the exploration of space by artificial satellites major scientific effort was directed largely towards the study of the nearearth environment. Due, in part, to the special technological problems involved, astronomical observations from satellites have become an established sub-discipline only in the last few years. In one important area, radio-astronomical observations at wavelengths beyond the limits of the ionospheric window, the pioneering work was confined to a very small group among whom were F. T. HADDOCK of the University of Michigan, A. E. LIILEY of Harvard University, J. H. ChapMan of DRTE, and F. G SMITH of Cambridge University. Stimulated by the efforts of these workers and discussions with other astronomers, the Goddard Space Flight Center began to study the development of a satellite radio telescope in 1962. This program included a survey of the astronomical observations most readily and profitably performed by an orbiting radio observatory, analysis of the antenna configurations most appropriate for such a mission, and the study of radiometers and other supporting instrumentation required for a radio astronomy satellite. The study culminated in the conceptual design of a spacecraft intended solely for radio astronomical observations at wavelengths beyond the ionospheric cut-off.

Extrapolation of theoretical models and Alouette satellite measurements of the ionospheric electron density distribution below $1000 \mathrm{~km}$ have been combined with experimental results obtained by the incoherent scatter technique at the geomagnetic equator to predict the expected variations of electron plasma frequency with altitude and time (R. E. Bourdead, private communication). At $6000 \mathrm{~km}$ the plasma frequency is expected to range from about 0.15 to $0.3 \mathrm{MHz}$. Although this is only an approximate picture, there is sufficient experimental evidence to conclude that, at this altitude, radio astronomical measurements can be made down to $0.3 \mathrm{MHz}$ independent of latitude and diurnal time.

This report describes the major features of the proposed design which provides for measurement of cosmic radio noise below $10 \mathrm{MHz}$ with a directive antenna. In the first section we briefly summarize the scientific objectives of the satellite experiment. The second and third sections are devoted to discussion of the antenna concepts and electronics, respectively. The salient features of the proposed radio astronomy satellite are then summarized in the final section.

\section{SCIENTIFIC OBJECTIVES}

Galactic Studics. -- By mapping the distribution of cosmic radio noise at frequencies below $10 \mathrm{MHz}$, it should be possible to estimate the emissivity of source regions in the Galaxy and thereby infer information regarding the galactic magnetic fields and the relativistic electron spectrum. If the relativistic electrons are produced in the formation of cosmic rays, we may have a method of studying the problem of cosmic ray formation in the Galaxy. From observations of the change in the synchrotron emission spectrum due to freefree absorption in $\mathrm{H}$ II regions we may estimate distances to the $\mathrm{H} \mathrm{II}$ regions as well as electron densities and/or temperatures for assumed galactic models by measuring optical depth. Since other loss mechanisms such as Bremsstrahlung, inverse Compton effect, and ionization also may be expected to affect the observed radio noise spectrum, its interpretation will never be a completely clear-cut matter. Nevertheless, observations of the spectral and spatial distribution of low frequency cosmic noise will provide a significant new source of information regarding the composition of the galaxy.

Solar Physics. - By making measurements over the frequency range of 0.3 to $20 \mathrm{MHz}$ it will be possible to observe burst activity at altitudes ranging from about 3 to 20 solar radii in the corona. Observations of the flux spectra and low frequency limits of the different burst types may be expected to contribute to the adoption of a theory for the emission mechanism. Measurements of the duration and time decay of bursts of type II and III can be interpreted in terms of the coronal electron temperature and can facilitate the measurement of the temperature distribution in the corona for assumed electron density distributions. The measurements will therefore serve as a powerful tool for study of the interaction of solar corpuscular streams and the coronal plasma.

Planetary Studies. - The sporadic decameter noise bursts from Jupiter have been the subject of considerable attention in recent years, and yet the mechanism of this emission is still not clearly understood. Among the major factors which have hampered the study of the Jovian emission have been the effects of the earth's ionosphere ; however by observing from a spacecraft above the iono- 
sphere, one should be able to determine the spectrum of the bursts at frequencies well below $10 \mathrm{MLHz}$. Such data are of considerable importance in the determination or confirmation of a theory regarding the emission mechanism and its subsequent interpretation in terms of the structure of the Jovian magnetosphere. Similarly, observations of the dynamic spectra of the Jovian storms from above the ionosphere should simplify the problem of determining how much of the burst fine structure is due to the impulsive nature of the source and the effects of inhomogeneities in the interplanetary plasma.

Although similar noise storms have never been detected unambiguously from other planets, such a possibility cannot be entirely ruled out. The apparent similarity in the magnetospheres of the earth and Jupiter make the occurrence of terrestrial noise bursts quite likely, and such activity may already have been observed in earlier space experiments. The radio astronomy satellite will be able to detect and map magnetospheric radio noise activity above $300 \mathrm{kHz}$.

\section{Antenna Concepts}

In evaluating an antenna system for a first generation radio astronomy satellite, the following properties were considered :
1. The antenna must have sufficient directivity over a large enough band of frequencies to permit accomplishment of the scientific objectives discussed above.

2. The system must be a mechanically simple structure which can be deployed from the spacecraft.

3. The electrical characteristics of the antenna shall not be influenced significantly by the space environment.

After a careful consideration of various antenna types it was decided that a long linear antenna configuration could meet all of these requirements with the least degree of compromise. The " $\mathrm{V}$ " antenna was selected over a single linear antenna because it has a solid main lobe and much better side lobe suppression. By insertion of terminating resistances a quarter wavelength from the end of the antenna, the pattern can be made unidirectional with $18 \mathrm{db}$ of front-tc-back ratio over a band of frequencies. The basic antenna configuration consists of two V's back-to-back which allows a differential method to be utilized to attain a very high front-to-back ratio over the entire frequency range. This particular configuration also provides some additional advantages which will be discussed subsequently. Typical power patterns for the $\mathrm{V}$ antenna are shown in Figure 1 and 2.

Considering the system of four conductors which $-7 \mathrm{db}$

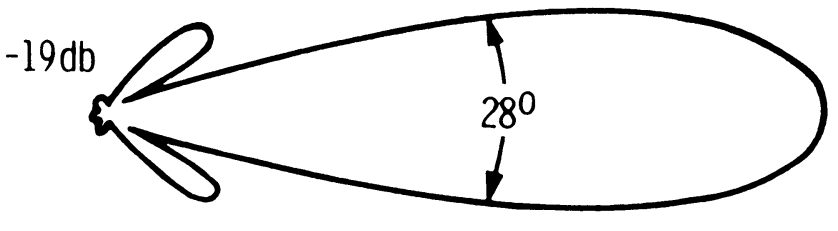

VERTICAL PLANE

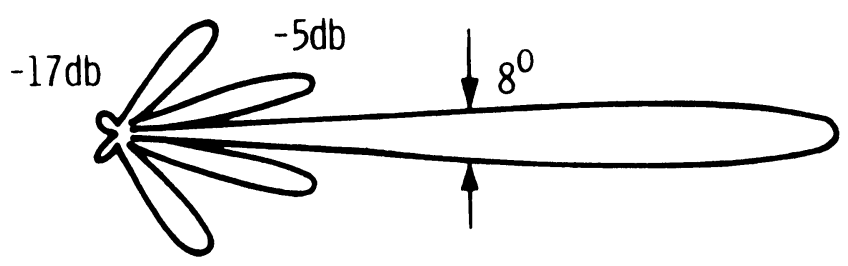

Fra. 1 - V antenna power patterns for $6.25 \lambda$ element length. 

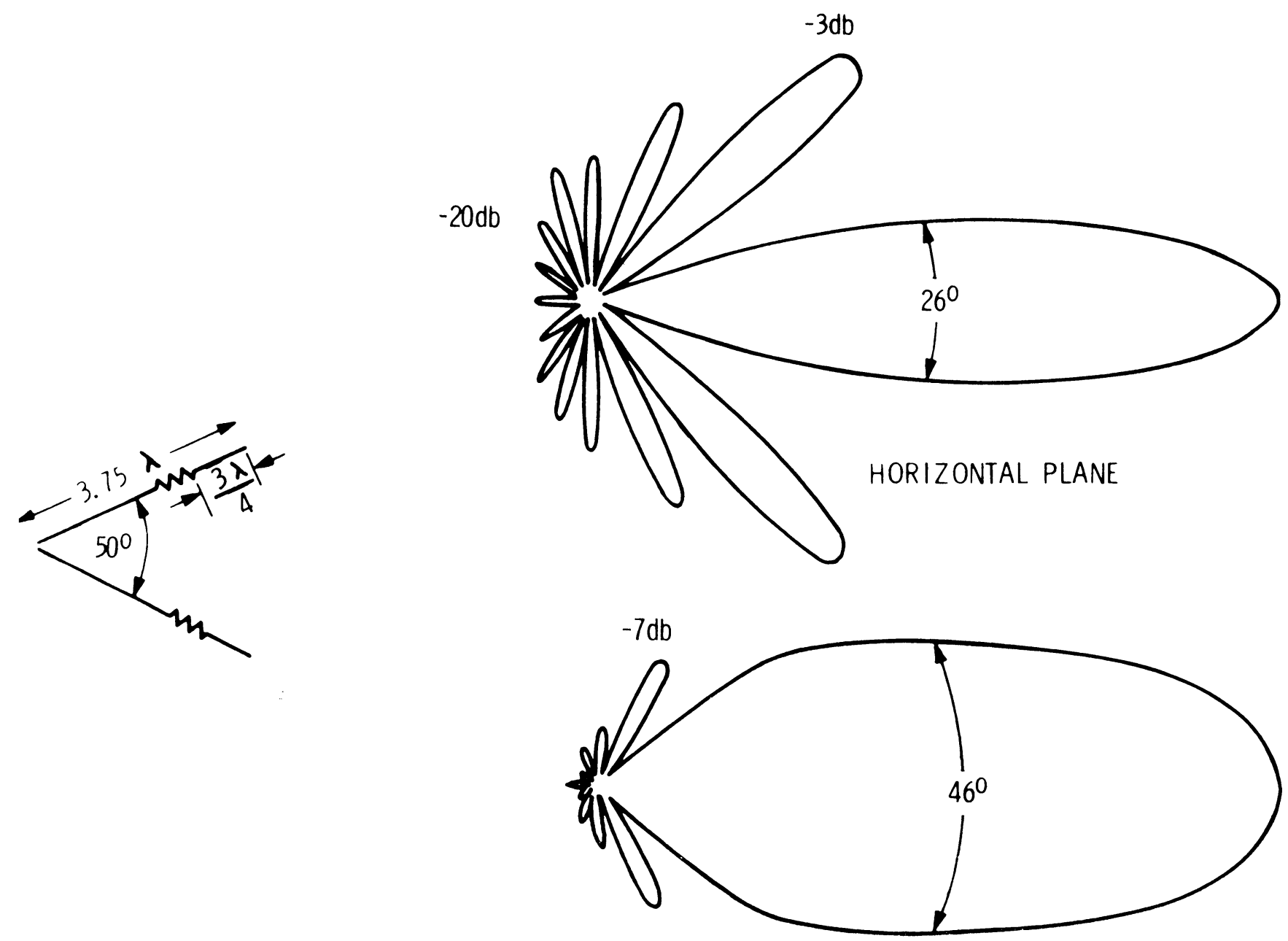

VERTICAL PLANE

Fig. 2. - V antenna power patterns for $3.75 \lambda$ element length.

forms the two $\mathrm{V}$ arrays, it is seen that several other configurations can be utilized for specific purposes. For example, we know that for a given length the patterns of $\mathrm{V}$ antennas with obtuse angles have greater directivity than $\mathrm{V}$ antennas with acute angles at the lower frequencies (below 1.5 MHz). Consequently, we can switch the four elements of the antenna system so that $\mathrm{V}$ antennas with both acute and obtuse angles will be used on a timesharing basis in order to obtain the maximum directivity at all frequencies.

A desirable but not imperative feature of the radic astronomy experiment is gravity-gradient attitude stabilization. It is desirable principally because $(a)$ it greatly facilitates the reduction of data and (b) it provides a convenient and important method of separating the celestial noise from terrestrial noise and from noise generated by the earth's radiation belt. Separation of extraterrestrial from terrestrial signals is made possible by the high front-to-back antenna gain ratios of the individual $\mathrm{V}$ antennas. Consider the principal mode of operation of the antenna elements where one acute angle $V$ antenna points toward the celestial sphere, the other toward the earth, each attached to identical but separate receiving systems. The two $\mathrm{V}$ antennas will resporid quite differently to the individual signals. Corisequently two equations with two unknowns will be telemetered and as a result the extraterrestrial and terrestrial components separately extracted in the data reduction process.

The four 250-meter elements which comprise the double-V antenna system will be extended by 

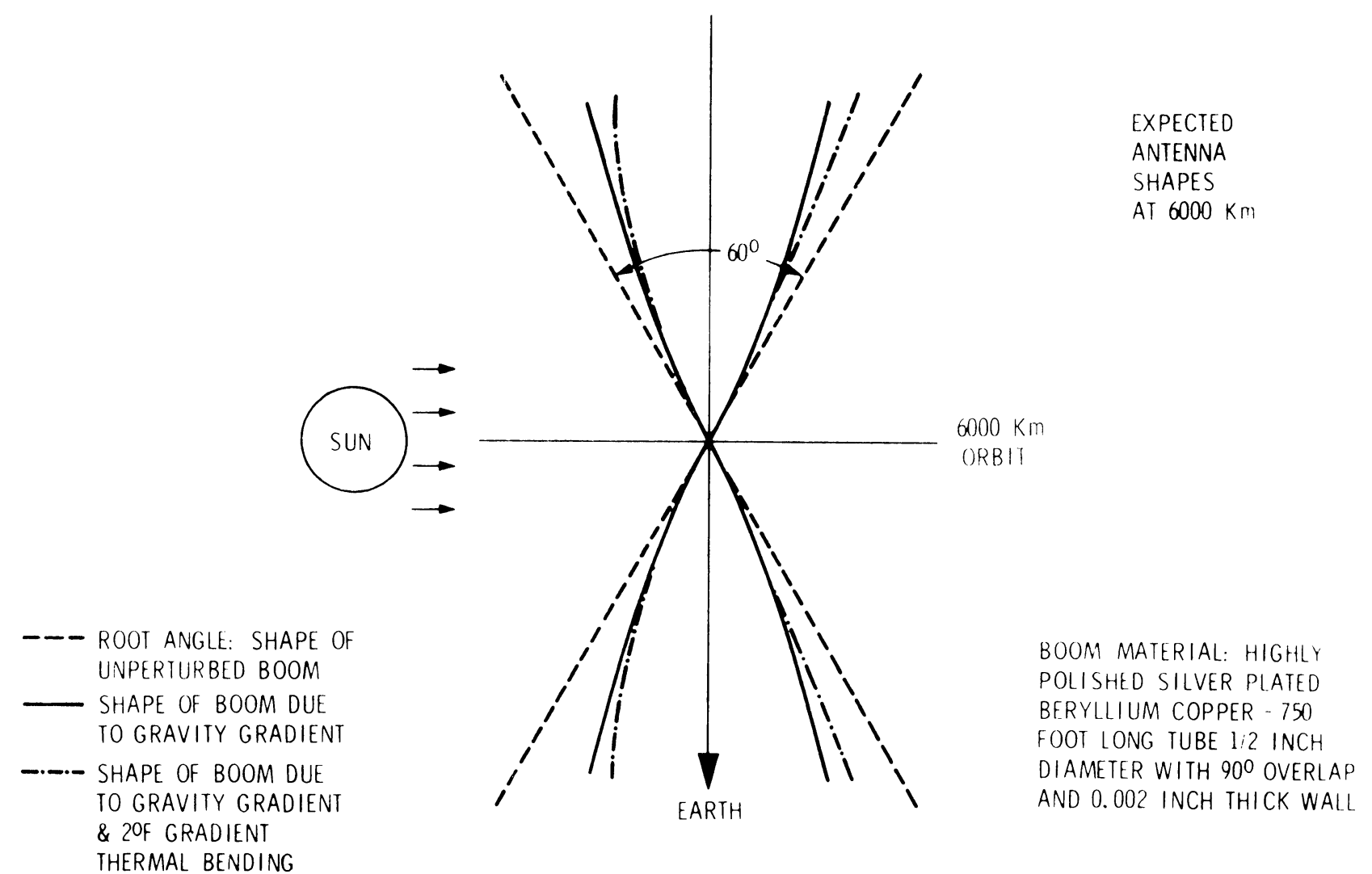

Fia. 3. - Expected shape of antenna booms at $600 \mathrm{~km}$ altitude showing bending due to gravitational and thermal forces.

use of a motor-driven system similar to that used for the 25-meter antenna elements on the Alouette satellite. Figure 3 shows the shape of the booms expected due to the combined effects of gravitygradient, centrifugal, and thermal forces (J. V. FEDOR, private communication). Tests have shown that this amount of bending will not disturb the antenna's electrical characteristics appreciably since the antenna root angle can be adjusted to produce a satisfactory " apparent" acute angle of the $V$, thus off-setting the effects of curvature.

The directive $\mathrm{V}$ antennas will not always be pointed in the right direction to permit observations of such special events as some types of solar and Jovian bursts of short time duration. These particular events will be monitored with a relatively non-directive short dipole antenna mounted perpendicular to the plane of the $\mathrm{V}$ antenna.

\section{RADIOMETERS AND SUPPORTING ELECTRONICS}

The basic instrumentation for a radio astronomy satellite would consist of three step-frequency radiometers, three antenna impedance probes, a fast burst radiometer, and supporting electronics such as plasma parameter probes and vehicle aspect sensors. A block diagram of the system is shown in Figure 4.

For long term, unattended operation use of the RYLE-VONBERG closed-loop radiometer is the most desirable technique for noise measurement since it has the advantages of accuracy and stability even in the event of variations in receiver yain and bandwidth. Figure 5 is a schematic diagram of such a radiometer of the type being developed at GSFC under the direction of R. C. SOMERLOCK. It employs a narrow-band pre-amplifier and a local oscillator for each frequency of operation. Three separate tuned circuits are employed in each pre-amplifier to provide isolation and protection from cross-modulation. The pre-amplifiers are followed by a wide-band RF amplifier and a balanced mixer where the input signal is combined with the local oscillator signal at the same frequency to create a zero-IF system. The bandwidth of the system is determined by an IF filter which precedes the IF amplifier. The output signal is synchronously demodulated in a phase detector driven by the reference oscillator which also drives the Dicke switch. The servo-loop is completed in the normal fashion by an integrator and a reference noise source whose output is maintained at 


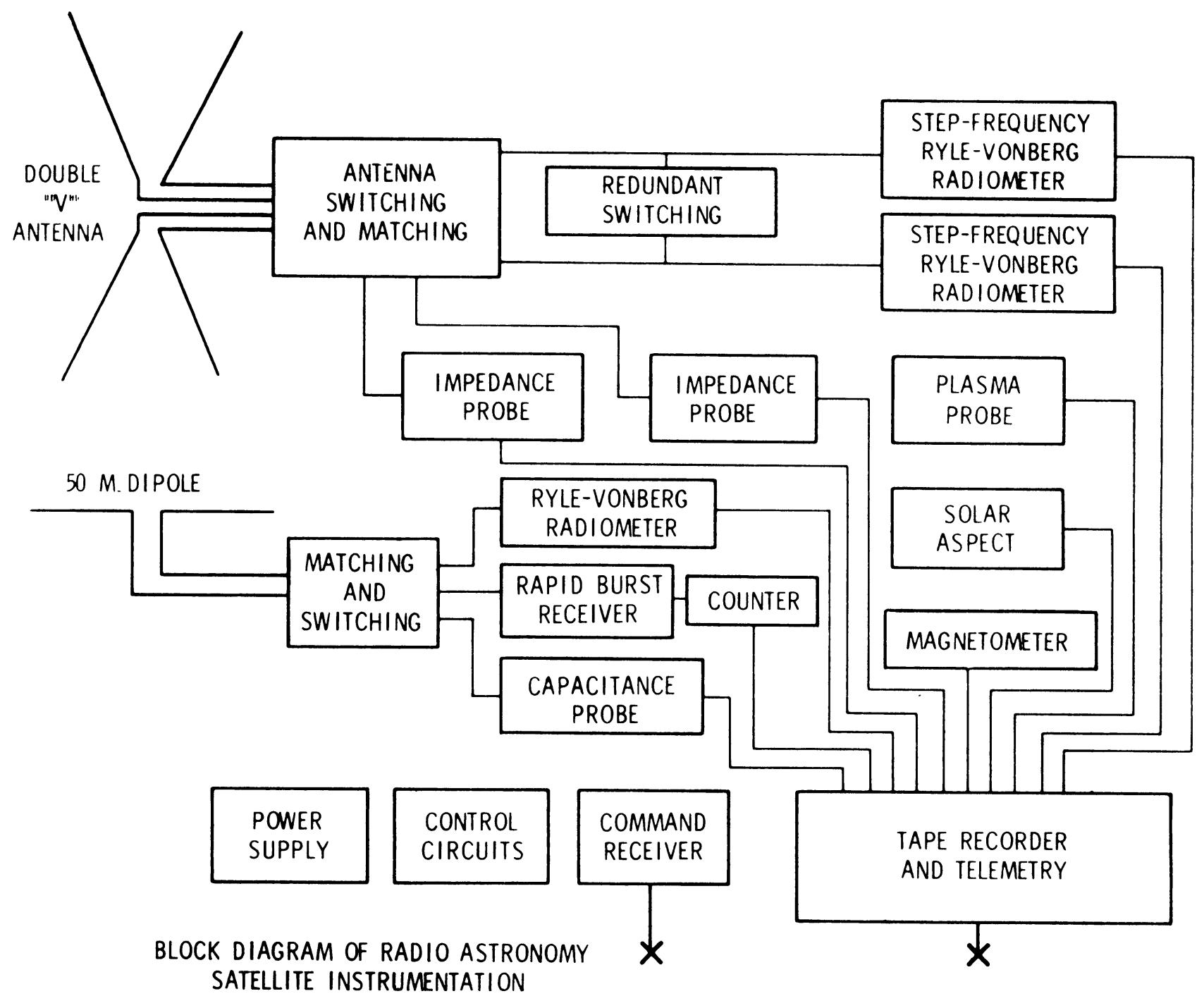

Frg. 4. - Block diagram of radio astronomy satellite instrumentation.

the level required to null the input signal from the antenna.

The all-solid-state noise source consists of an AGC-controlled, high-gain, wide-band amplifier which amplifies the thermal noise of the early stages, a narrow band filter centered on the operating frequency, and an output power amplifier stage. Since the noise source is capable of providing several milliwatts of output noise power, it is followed by a passive attenuator which reduces the noise to the required reference level within the $70 \mathrm{db}$ dynamic range of the system. In order to achieve optimum stability and accuracy, the noise source output (which is proportional to the power received by the antenna) is measured by a selfbalancing thermistor bridge.

In order to relate the power delivered to the radiometer to the actual power incident on the antenna one must know the antenna impedance. Since, at the lower observing frequencies, the antenna impedance may be modified by magnetoionic effects, considerable effort has been directed towards the development of a probe to measure both the real $(\mathrm{R})$ and imaginary $(\mathrm{X})$ components of antenna impedance $(\mathrm{Z})$, where

$$
|\mathrm{Z}|=\left(\mathrm{R}^{2}+\mathrm{X}^{2}\right)^{1 / 2} \text {. }
$$

One such probe, which has already been tested on a sounding rocket, is diagrammed in Figure 6 . A sensor picks off signals proportional to the antenna voltage, $\mathrm{V}$, and current, I, at a frequency, $f$. These are mixed with a signal at frequency $f-\Delta f$, and the two resultant signals at frequency $\Delta f$ are amplified and detected to provide outputs 


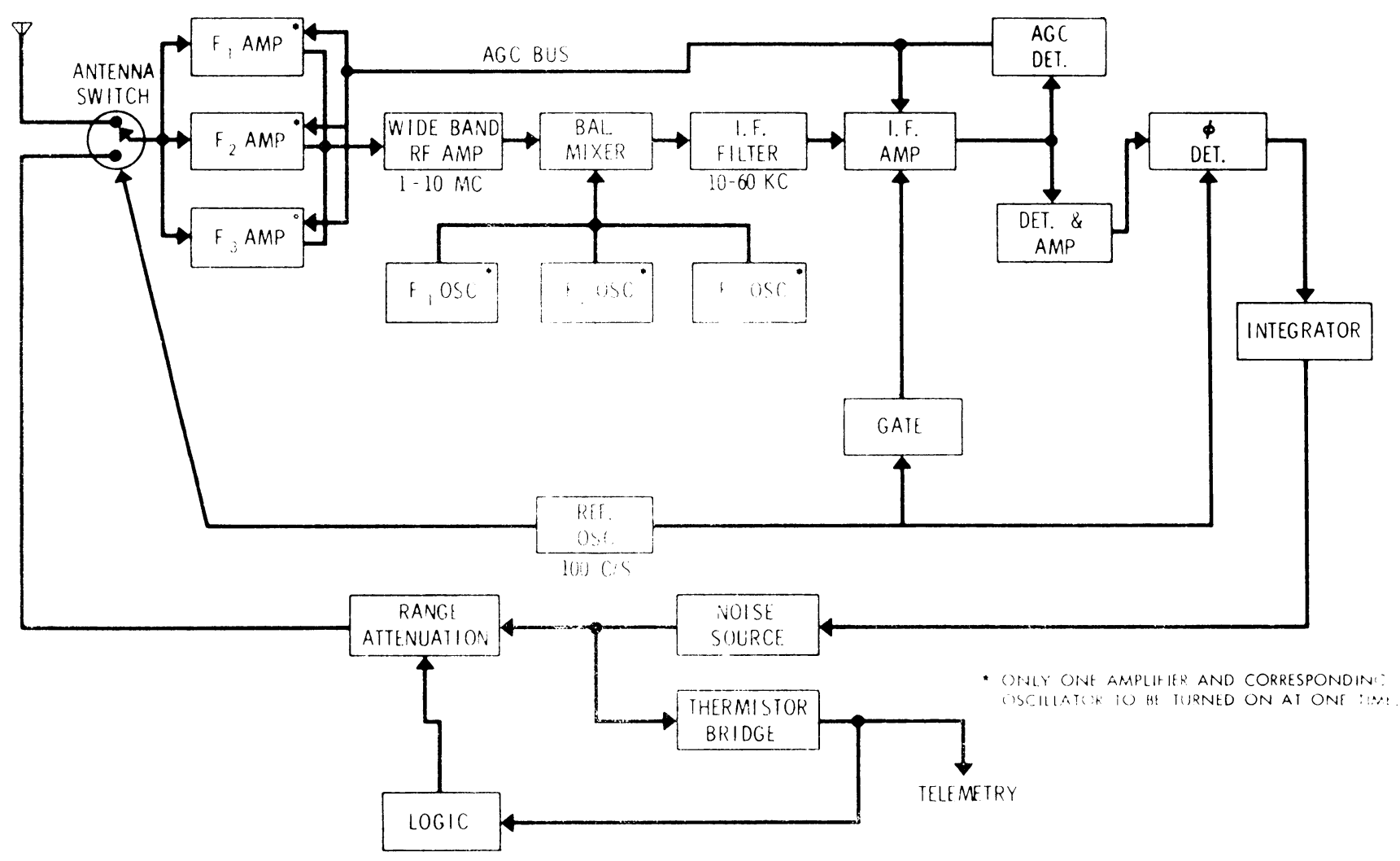

SPACECRAFT RADIOMETER BLOCK DIAGRAM

Fia. 5. -...- Block diagram of satellite radiometer.

proportional to $|\mathrm{V}|$ and $|\mathrm{I}|$. The two signals are also compared through a phase-sensitive detector to provide a measurement of phase, (D. An expander is included to allow high precision measurements of phase angle.

The fast burst radiometer used in conjunction with the short dipole antenna is designed to measure the characteristics of impulsive noise bursts such as solar Type III bursts. It will consist of four fixed-frequency receivers - all of which will be open to reception at the same time until a burst is detected. The presence of a burst will be established by the detection of a signal above some pre-set threshold, in which case the receiver will store the detected signal and shut itself off. The telemetry system will sample the receivers serially, and each receiver will be reactivated upon reading out its measured data. Upon reactivation, the cycle will repeat. The time between readings on any one channel will be about 160 milliseconds and will require about 20 milliseconds to perform a reading. By locking up a channel after a signal is detected and measuring its time of occurrence and amplitude and continuing in this fashion after each channel is read out, it is possible to measure the intensity, duration, and frequency drift of a burst.

\section{SUMMARY}

The system described above will readily meet the objectives of a first generation orbiting radio telescope with maximum simplicity and reliability.

\section{TABLE I}

Antenna

Leg Length ........ $250 \mathrm{M}$

$\checkmark$ Apex Angle ........ $50^{\circ}$

$3 \mathrm{db}$ Beamwidth ....... $26^{\circ} \times 46^{\circ}$ at $4.5 \mathrm{MHz}$ $8^{\circ} \times 28^{\circ}$ at $7.5 \mathrm{MHz}$

Front-to-Back Ratio , . . $18 \mathrm{db}$

\section{RADIOMETER}

Frequency Range ..... 0.3 to $20 \mathrm{MHz}$ in 10 steps Bandwidth ......... $20 \mathrm{kHz}$

Noise Figure $\ldots \ldots \ldots<<8 \mathrm{db}$

Dynamic Range ..... $>70 \mathrm{db}$

Relative Accuracy $\ldots \ldots \pm 0.5 \mathrm{db}$ 


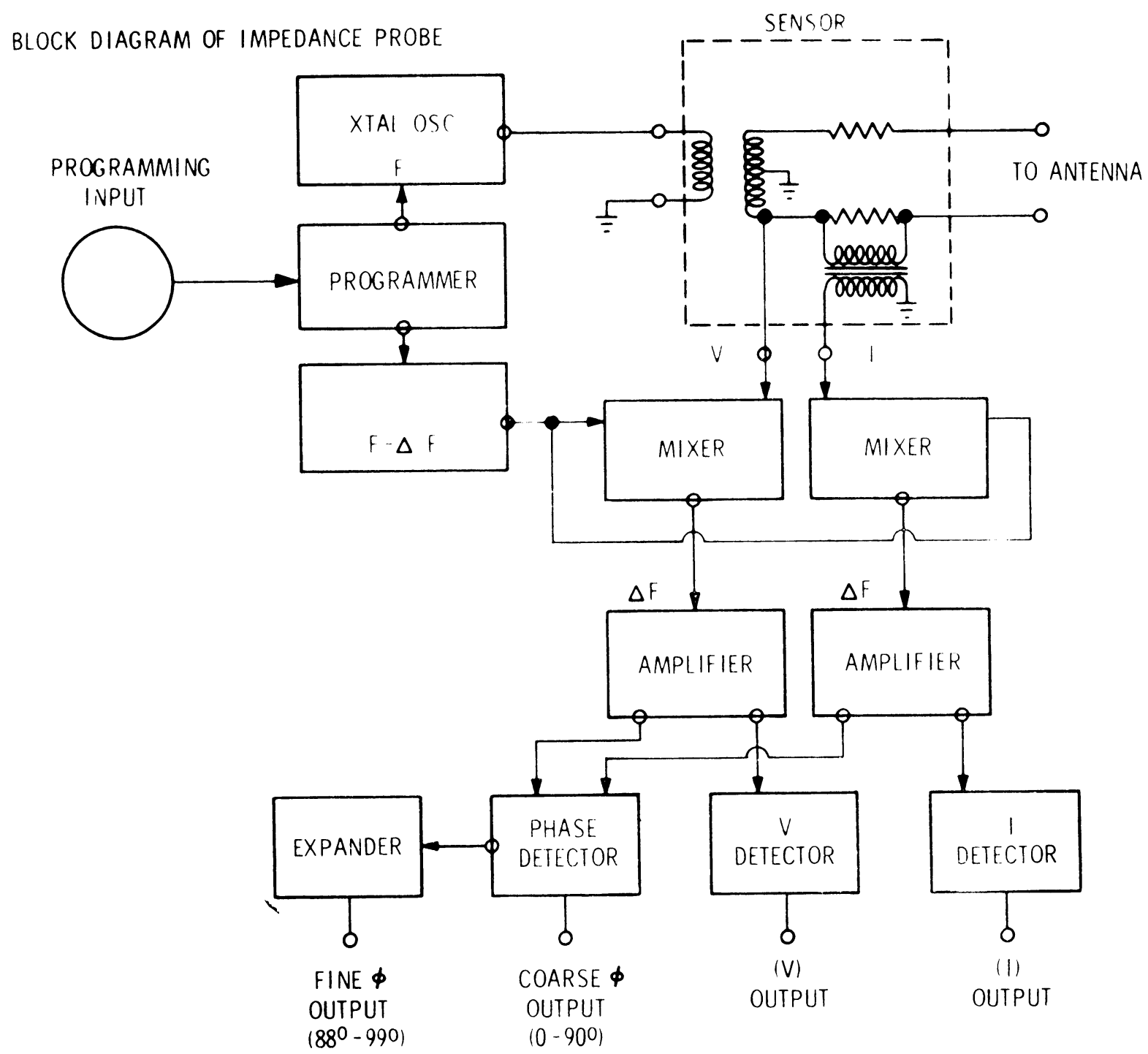

Fic. 6. - Block diagram of satellite antenna impedance probe.

Use of the acute angle $\mathrm{V}$ antenna will provide directive maps of the galactic noise background at several frequencies in the 1.5 to $10 \mathrm{MHz}$ range. By properly utilizing switched combinations of the $\mathrm{V}$ booms and the "short" dipole antenna, less directive measurements and integrated noise values can be unambiguously cbtained down to $0.3 \mathrm{MHz}$. Observations at a frequency near $20 \mathrm{MHz}$ furthermore, will provide a " bridge " to the lowest frequency ground-based measurements. The salient features of the proposed antenna and radiometer are briefly listed in Table I.

Since the system under consideration is estimated to weigh 275 to $300 \mathrm{lb}$ (125 to $135 \mathrm{~kg}$ ) it can be placed in a $6000 \mathrm{~km}$ altitude, $50^{\circ}$ inclination, circular orbit with a relatively low cost launch vehicle. A gravity-gradient stabilized antenna in such an orbit would provide a scan of the sky at an angular rate of about $1.5 \% / \mathrm{min}$ while orbit precession would afford coverage of almast the entire celestial sphere in about one year. The experiment should provide valuable insight to the physics of the Galaxy, the Sun, and the planetary system and should lead to the development of more sophisticated systems for radio astronomical observations from space.

Manuscrit reçu le 22 août 1964. 